Chapter 28

\title{
Improving Drug Policy Metrics and Advancements in Measuring Gender-based Drug Policy Outcomes
}

\author{
Marie Nougier
}

\section{Introduction}

Over the past five years, the amount of research on women and drugs has increased exponentially, from the specific harms faced by women who use drugs and the devastating consequences of over-incarceration of women for minor drug offences, to the role played by women in illicit crop cultivation and how development programmes are leaving them behind. And yet, much more research and data collection are needed to truly understand how drugs - and importantly drug policies - affect women.

The need for both quantitative and qualitative data and analysis of how and why women are involved in the illicit drug trade cannot be understated. There is a lack of adequate indicators to track the diversity of women engaged in illicit drug activities, the underlying factors of their engagement in the trade, the differentiated impacts that both drugs and drug policies might have on their lives, and the specific vulnerabilities they may face. Advancing research on these factors can allow policy makers to design and implement drug policies that are truly effective to promote and protect the health, human rights, socio-economic development and security of women in contact with the illicit drug market. To date, however, and despite recent progress, the complex ways in which drug control efforts have impacted upon the lives of women worldwide have taken the backstage in global drug policy.

This chapter provides a historical analysis of how data on women has been collected by the United Nations (UN), while assessing opportunities for the identification of more meaningful indicators. In conducting this analysis, the

\footnotetext{
The Impact of Global Drug Policy on Women: Shifting the Needle, 247-256

Copyright $(C) 2021$ by Marie Nougier

These works are published under the Creative Commons Attribution (CC BY 4.0) licence. Anyone may reproduce, distribute, translate and create derivative works of these works (for both commercial and non-commercial purposes), subject to full attribution to the original publication and authors. The full terms of this licence may be seen at http://creativecommons.org/licences/by/4.0/legalcode doi:10.1108/978-1-83982-882-920200034
} 
author only considers gender-related issues associated with women, as debates on LGBTQ+ communities have unfortunately not yet made it into UN drug control debates.

\section{'Women': The Missing Component of Drug Policy}

Historically, the issues faced by women, and a consideration of their specific needs in drug policy, have been generally ignored by UN policy makers in Vienna. This can be traced back to the UN drug control conventions themselves, concerned with the 'health and welfare of mankind' (emphasis added), which make no mention of 'gender' or 'women' (United Nations, 1961, 1971).

The first reference to women in high-level UN documents on drugs dates back to 1998, in the Political Declaration adopted at the second UNGASS on drugs, which called on member states to 'to ensure that women and men benefit equally, and without discrimination, from strategies directed against the world drug problem, through their involvement in all stages of programmes and policy-making', and affirming the international community's

determination to provide the necessary resources for treatment and rehabilitation and to enable social reintegration to restore dignity and hope to children, youth, women and men who have become drug abusers. (United Nations General Assembly, 1998, p. 3)

It is worth noting here how the latter phrasing is heavily ideologically charged.

It was only in the 2009 Political Declaration and Plan of Action on drugs that UN member states were called upon to 'take into account the specific needs and circumstances that women face with regard to drug problems' and to 'undertake effective measures to ensure that women, as well as men, have access to, and benefit equally and without discrimination from, drug control policies'. The Plan of Action accompanying the Political Declaration acknowledged the reality that demand reduction interventions were not tailored to vulnerable groups with specific needs, in particular 'women, including pregnant women'. It called on member states to 'Ensure that a broad range of demand reduction services, including those in the areas of prevention, treatment, rehabilitation and related support services' ('related support services' being understood by various member states as referring to harm reduction [Commission on Narcotic Drugs (CND), 2009a, p. 119]) and to:

provide approaches that serve the needs of vulnerable groups and are differentiated on the basis of scientific evidence so that they respond best to the needs of those groups, taking into account gender considerations and cultural background. (CND, 2009b, pp. 9, 23)

Those aspects, however, exclusively focus on the demand side of drug policy.

The limited focus on women in the 2009 Political Declaration and Plan of Action was reflected in the Annual Report Questionnaire (ARQ) (United Nations 
Office on Drugs and Crime (UNODC) Statistics and Data, 2019), adopted just a year later by the CND, and which remains in use today (CND, 2010). The ARQ is the data collection tool sent each year by the UNODC to member states, in order to assess key trends in the illicit drug market. Data collected via the ARQ constitute the basis of the yearly World Drug Reports and the UNODC Executive Director's biennial reports on the implementation of the 2009 Political Declaration and Plan of Action (United Nations Office on Drugs and Crime (UNODC), 2012, 2014, 2016b, 2018c).

The ARQ as it currently stands is organised under four headings: Part I: Legislative and institutional framework; Part II: Comprehensive approach to drug demand reduction and supply; Part II: Extent and patterns of drug use; and Part IV: Extent and patterns of and trends in drug crop cultivation and drug manufacture and trafficking. Under these headings, member states are requested to submit data on women in relation to the prevalence of drug use (Q9-11, 15-17 of Part III) and the percentage of people accessing drug dependence treatment who are women (Q65, Part III). However, there is no gender-specific data being collected on the prevalence of injecting drug use and 'severe drug use' or on drug use prevalence among marginalised communities (homeless people, people engaged in sex work, and people in prisons); on access to needles and syringe programmes; on the prevalence of infectious diseases among people who inject drugs in the community and in prison; on non-fatal overdoses; and on drug-related deaths.

The dearth of requests for gender-specific data in the area of 'supply reduction' is even more pronounced, with data only being collected in relation to alternative development programmes. Even then, the ARQ only requests information on the general question of whether gender-related actions and measures are included when planning and implementing alternative development programmes (Part II) and the number of people in contact with the police and/or the criminal justice system for consumption offences and for trafficking offences (Q 25-26, Part IV).

As a result, only a few references to the issues faced by women were made in the subsequent biennial reports of the UNODC Executive Director, mostly in the area of alternative development, but none on women who use drugs (UNODC, 2012, 2014, 2016b, 2018c). In 2018, this led the Executive Director to conclude that

With regard to demand reduction and related measures, the Commission might wish to consider recommending that member states [...] Develop drug prevention and treatment strategies that are easily accessible by and tailored to the specific needs of young people (both boys and girls) and women, in particular pregnant women. (UNODC, 2018c)

As for the World Drug Reports, it was not until 2018 that the UNODC dedicated a whole booklet to the issue of 'women and drugs', in which the Office deplored the lack of gender-disaggregated data, especially in cultivation areas (UNODC, 2018a). 
In addition to the lack of gender focus in data collection, a closer look at the ARQ as currently framed shows an overwhelming focus on the scale of the illicit drug market, with little to no regard to the actual impacts of drug policy on people's - and in particular women's - lives, wellbeing and human rights. For instance, when assessing whether alternative development programmes have a gender focus, no data is being collected on whether this has resulted in more equality in access to and ownership of land, or on increased income generation for both men and women. Similarly, data collection on the criminal justice system focusses on numbers of people incarcerated, but does not look into the profile and specific characteristics of male and female offenders. This is despite the fact that the Bangkok Rules invite 'Member States to collect, maintain, analyse and publish, as appropriate, specific data on women in prison and women offenders'. Rule 67 in particular calls on member states

to organize and promote comprehensive, result-oriented research on the offences committed by women, the reasons that trigger women's confrontation with the criminal justice system, the impact of secondary criminalization and imprisonment on women, the characteristics of women offenders, as well as programmes designed to reduce reoffending by women, as a basis for effective planning, programme development and policy formulation to respond to the social reintegration needs of women offenders. (UN General Assembly, 2010, p. 20)

This is one of the critical failures of the current ARQ, which came particularly to light in the aftermath of the latest UNGASS on drugs, held in April 2016.

\section{The 2016 UNGASS and its Aftermath: Gender Issues Come to the Fore}

The UNGASS was a catalyst moment for the UN, governments and civil society to highlight the specific vulnerabilities and needs of women engaged in, or affected by, the illicit drug trade and drug policies. In the lead up to the Special Session, UN Women released a landmark report documenting 'how the world drug problem and drug control regimes intersect with gender equality and women's empowerment' (UN Women, 2014, p. 1). UN Women raised concerns over the toll of repressive drug control on the incarceration of women in the Americas, calling for member states to avoid "criminalizing the most vulnerable in the chain of drug production and drug trafficking, including the possibility of decriminalising drug use and low-level, non-violent drug offenses'. Many of these considerations were also raised in the United Nations Development Programme's (UNDP's) own written contribution to the Special Session (UNDP, 2015).

Importantly, the UN Women brief concluded that 'we need many more countries to collect and use sex-disaggregated data' and 'country-specific information about how the drug trade affects women's security, why women become involved 
in drug use and drug trafficking - including through coercion -, and about women's experience of accessing justice for drug-related crimes or social and medical services for drug use' (UN Women, 2014, pp. 2, 3). This recommendation was taken on-board by the CND in 2016 with Resolution 59/5 on 'Mainstreaming a gender perspective in drug-related policies and programmes' (CND, 2016), which

Encourages Member States to collect and share quantitative and qualitative data, disaggregated by age and sex, related to the world drug problem, including when providing information through the annual report questionnaire as well as when reporting to the Commission on Narcotic Drugs..., and to mainstream a gender perspective in their research and analysis on the various aspects of the world drug problem, with a view to addressing the knowledge gap on women and drug use. (OP 2 of Resolution 59/5, p. 3, emphasis added)

This resolution was negotiated at the same time as the UNGASS Outcome Document, which likely contributed to the inclusion of the strongest language to date on women in such a high-level political document. Chapter 4 of the Outcome Document, which was entirely dedicated to 'cross-cutting issues: drugs and human rights, youth, children, women and communities' called on member states to:

Mainstream a gender perspective into and ensure the involvement of women in all stages of the development, implementation, monitoring and evaluation of drug policies and programmes, develop and disseminate gender-sensitive and age-appropriate measures that take into account the specific needs and circumstances faced by women and girls with regard to the world drug problem and, as States parties, implement the Convention on the Elimination of All Forms of Discrimination against Women. (OP 4.g of the UNGASS Outcome Document, p. 15)

The preamble of the UNGASS Outcome Document also recognised that 'targeted interventions that are based on the collection and analysis of data, including age- and gender-related data can be particularly effective in meeting the specific needs of drug-affected populations and communities'.

These considerations are critical as the CND is once again reviewing the ARQ. Indeed, in March 2019, the Ministerial Declaration adopted at the occasion of the Ministerial Segment on the 'world drug problem' committed the international community to ensure 'that collection of reliable and comparable data, through a strengthened and streamlined annual report questionnaire, reflects all commitments'. The 2019 Declaration also recognised

the importance of appropriately mainstreaming a gender and age perspective into drug-related policies and programmes and that 
appropriate emphasis should be placed on individuals, families, communities and society as a whole, with a particular focus on women, children and youth, with a view to promoting and protecting health, including access to treatment, safety and the well-being of all humanity. (CND, 2019, p. 2, emphasis added)

The review of the ARQ, initiated by the UNODC in 2018, provides a key opportunity to incorporate indicators that can better reflect, and track progress against, gender-sensitive drug policies and their impacts on their health and wellbeing. However, whether the UNODC does indeed achieve this goal remains to be seen.

\section{The ARQ Review Process: A Missed Opportunity?}

The ARQ review process constitutes an important opportunity to incorporate aspects from the UNGASS Outcome Document - including its operational recommendations on women - and to re-balance the overall Questionnaire away from a focus only on the scale of demand and supply, and towards a more comprehensive evaluation of the complex relationship between drugs and drug policy, health, human rights, security and development, and how this relates to women. Following this line of thinking, in 2018, the Office of the High Commissioner for Human Rights (OHCHR) encouraged member states 'to collect up-to-date, comprehensive, disaggregated and transparent data on drug control efforts.' The data gathered

should be used by States to analyse the impact of drug control efforts on the enjoyment of human rights, and to enhance compliance with international human rights norms and standards in the administration of drug policies. (OHCHR, 2018, p. 17)

When the ARQ review process was launched in 2018, after years of advocacy from civil society and governments (in particular Switzerland), there were high hopes that the OHCHR recommendation might finally make a dent in a system that had so far resisted any inclusion of human rights language. To kick off the discussions, the UNODC held a first expert consultation on 'Improving drug statistics and strengthening the Annual Report Questionnaire (ARQ)' in January 2018, gathering governments and various UN agencies (UNODC, 2018e). Following the adoption of the Ministerial Declaration, the UNODC initiated a second round of consultations, with a meeting of UN, international and regional agencies held in May 2019, followed by a second expert consultation for member states in August 2019. It should be noted that none of these meetings involved civil society, despite repeated calls for inclusion from various NGOs with expertise in this area.

Ahead of the August consultation, a new draft ARQ was shared by the UNODC (UNODC, 2019c). Although at the time of writing the draft was still under review, the format of the ARQ significantly shifted, mostly for the better. 
Instead of four lengthy, complex and at times repetitive sections, the new draft included a greater number of shorter and more focussed modules, eleven that will be shared annually, and another sixteen rotating modules that would be sent out less frequently. Interestingly, the new draft adopts a granular approach - with key data being requested by all member states, and sub-questions for those wishing (and able) to provide further information. Positively, these sub-questions focus on substantive socio-economic issues and vulnerabilities, including for women involved in the illicit drug trade. This approach was meant to acknowledge the capacity challenges faced by many countries in collecting data on drugs.

Nevertheless, challenges remain. Efforts were made in the latest version to improve gender-disaggregated data in most aspects of the ARQ, in particular the modules focussing on drug demand issues. However, the issue remains that mere data disaggregation is not enough, and efforts to improve the ARQ are falling short of adequately tracking data on how and why women engage in the illicit drug trade, their age, their ethnicity, their socio-economic status, their family situation, and any history of trauma, violence, mental illness, stigma and discriminations they might have faced as part of drug control efforts. Considering the current state of play, and the political complexities of decision-making at the CND in Vienna, the ARQ alone is unlikely to be sufficient to collect much-needed data on women. In addition, the ARQ is only filled in by about half of UN member states, mostly based in the Global North, and there are therefore severe gaps in data available through that tool. This means that other tools should be leveraged to assess the differentiated impacts of drug policy on women.

\section{Leveraging UN Human Rights Mechanisms}

Over the past four years, much progress has been made within UN agencies in Geneva to analyse drug policy issues within their respective mandates. The OHCHR has led the charge in this respect, thanks to a mandate provided by the first-ever resolution on drugs and human rights adopted in 2015 by the Human Rights Council (HRC), in preparation for the 2016 UNGASS (HRC, 2015). The resulting OHCHR report, presented as an official written contribution for the UNGASS, dedicates an entire section to the various consequences of drug control on women, including mass incarceration, exacerbation of poverty, the ongoing criminalisation of pregnant women who use drugs and mothers, discrimination in access to health services, as well as physical violence at the hands of law enforcement officers, to name a few (OHCHR, 2015).

Three years later, the HRC followed up on Resolution 28/28 with a second resolution focussing on the human rights implications of UNGASS implementation (HRC, 2018), prompting a second landmark report by the OHCHR on the issue. In addition to streamlining the various concerns relating to women throughout the report, the OHCHR once again allocated an entire section to women. In its recommendations, the OHCHR called on member states to:

adapt their drug policies to address the specific needs of women, children and youth, and members of groups in a situation of 
vulnerability', and for the first time expanding this recommendation to 'lesbian, gay, bisexual, transgender and intersex persons'. (OHCHR, 2018)

The 2018 OHCHR report also highlighted the large array of reports, conclusions and recommendations by Special Procedures related to women and drugs, including by the Special Rapporteur on violence against women in the context of women's over-incarceration for minor, non-violent drug offences, and the Working Group on Arbitrary Detention (OHCHR, 2018). More recently, the UN Working Group on the issue of discrimination against women in law and in practice launched a report on women deprived of liberty, raising major concerns around the lengthy prison sentences and over-representation of women incarcerated for drug offences, and the severe consequences of punitive drug laws on their lives and that of their families. This prompted the Working Group to call on states to:

Reform drug-related policies, laws and practices in line with international human rights standards and take steps to integrate the International Guidelines on Human Rights and Drug Policy into policies that are relevant to women. (Working Group on the Issue of Discrimination against Women in Law and in Practice, 2019)

The Committee on the Elimination of Discrimination against Women (CEDAW) has also developed an extensive jurisprudence around the 'excessive use of incarceration' against women for drug offences and the need for gendersensitive alternatives, the rights of rural women in drug policy, and the many forms of discrimination faced by women who use drugs in seeking access to health and harm reduction services. Similarly, the Committee on Economic, Social and Cultural Rights (CESCR) has recommended that member states incorporate gender-sensitive approaches into their national drug strategies (OHCHR, 2018).

As the OHCHR, Special Procedures and UN human rights treaty bodies such as CEDAW and the CESCR continue to review country performances against their human rights commitments, it will be up to civil society to systematically raise concerns around how drug policies impact upon the rights of women, thereby ensuring that these issues feature prominently and regularly within the mandates and work of UN agencies based in Geneva - hence building an alternative source of data collection on women and drug policy that could feed into $\mathrm{UN}$ decision-making processes on drugs in Vienna. For instance, the upcoming reports from the OHCHR on the human rights situation in the Philippines (OHCHR, 2019a) and from the Working Group on Arbitrary Detentions regarding drug policy (HRC, 2019) are key opportunities in this regard.

\section{Leveraging the Sustainable Development Goals}

Yet, another critical avenue for collecting more data on women and drugs is the 2030 Agenda for Sustainable Development and its associated Sustainable 
Development Goals (SDGs). The SDGs will celebrate their five-year anniversary in 2020, and promote a strong gender focus in all aspects of policy-making, in particular via SDG 5 'Achieve gender equality and empower all women and girls'. Various indicators within SDG 5 are particularly relevant when tracking progress in drug policy, especially those relating to ending all forms of discriminations against women (indicator 5.1), eliminating all forms of violence against women (indicator 5.2), ensuring women's participation in decision making (indicator 5.5), ensuring universal access to sexual and reproductive health (indicator 5.6), giving women equal rights to economic resources and ownership and control over land (indicator 5.A), and adopting policies to empower women and promote gender equality (indicator 5.C). Beyond SDG 5, the issues affecting women in drug policy are relevant to many other SDGs, including those focussing on poverty (SDG 1), health (SDG 3) and justice (SDG 16).

Nevertheless, how drugs and drug policy affect women has so far been subject to little visibility within the SDG discussions. Voluntary reporting by countries for the yearly High Level Political Forums has not featured any strong focus on drugs issues in general, and only a fraction of countries mentioned both women and drugs in their contributions in 2017, when SDG 5 was under review. This was the case for Nigeria, which briefly mentioned the coverage of drug dependence treatment interventions for both men and women (Federal Republic of Nigeria, 2017), for Afghanistan which discussed HIV and injecting drug use, including among women (Afghanistan, 2017) and Chile, which briefly described a programme centred on a small focal group of women in an area particularly vulnerable to drug trafficking (Chile, 2017). The key opportunities granted by the SDGs in collecting more data on women and drugs have therefore not been leveraged adequately, either by civil society or by governments - an issue that should be addressed urgently between now and 2030 .

\section{Civil Society: A Critical Player for Evaluating the Impacts of Drug Policy on Women}

Although data collected by the UN and its member states remains crucial to better understand the conditions in which women engage in the illicit drug trade and how drug policies affect them, civil society has a clear role to play in providing a more complete picture. A number of NGOs working on issues as varied as drug policy, human rights, feminism, criminal justice reform, prisons, palliative care and healthcare have recently produced qualitative reports on the many ways in which drug policies affect women. This includes, for instance, muchneeded research conducted by NGOs such as Dejusticia in Colombia, Equis Justicia para las Mujeres in Mexico, NoBox Philippines or LBH Masyarakat in Indonesia on women incarcerated for drug offences in both Latin America and Asia, aiming to better understand the multifaceted vulnerabilities women and their families are facing, and how drug policies could be reformed to better address their needs.

Another key role played by civil society is to create space for affected women to talk to their policymakers about their lived experience, and advise them on 
what should be changed. In the area of drug use, networks such as the Women and Harm Reduction International Network or the Eurasian Harm Reduction Association work to ensure that the rights of women who use drugs are respected and promoted. In Spain, the NGO Metzineres, a harm reduction service led by women, aims to empower women who use drugs to claim their rights, shape the services they need and collect research and data to gain a better understanding of women's needs and desires. The International Drug Policy Consortium and Washington Office on Latin America have also been instrumental in facilitating the participation of affected women in policy debates at national, regional and UN levels.

Research by civil society is particularly important to fill the gaps in research on questions that might be considered to be irrelevant by governments and the UN. If one takes the example of women who use drugs, the ARQ might collect data on the number of women who use drugs and of those having access to sterile needles and syringes. However, NGO data can provide a better understanding of why women might have more restricted access to harm reduction services, including the high levels of stigma they are facing, the lack of services tailored to their specific needs, and the violence and intimidation they may face from healthcare workers and law enforcement officials. Only a true understanding of these complex issues will ensure that drug policies are both effective and rights-based.

\section{Conclusion}

The importance of good-quality, reliable and systematic data cannot be understated in the design and implementation of evidence-based drug policies. However, the continued lack of understanding of how women interact with the illicit drug trade and are impacted by drug policies remains a major impediment to the elaboration of gender-sensitive policies and programmes. In a context where governments worldwide show ongoing reluctance to collect data on the needs and vulnerabilities of women in drug policy, it will be up to civil society and affected women to keep up the pressure through the various data collection mechanisms at their disposal, be it through the revised ARQ, UN human rights entities, or through much-needed qualitative research and analysis. 